\title{
5 años de Derecho Animal
}

Keywords: Derecho Animal; Derecho del Bienestar Animal; seres sintientes; denuncias por maltrato

En febrero del 2010 se publicó la primera edición de la web derechoanimal.info. Desde hace cinco años que se cumplen ahora, hemos tratado de llevar a cabo, con pasión, la idea que nos animó a iniciar este servicio en favor de los animales, desde la vertiente que nos es propia, que es la jurídica. Queríamos -entonces y ahora-, "ser un instrumento de formación y de información, serena, contrastada y segura, que interese tanto a profesionales del Derecho como a quienes no pertenecen al mundo jurídico".

Para ello buscamos un carácter diferenciador, respecto a otras webs existentes, que fue la de poner a disposición de todos -de una forma accesible, ágil y en constante renovación-, las herramientas de conocimiento del mundo jurídico en relación a los animales, hasta ese momento dispersos y desordenados, como eran la legislación y la jurisprudencia animal. Ahora puede parecer muy obvio, pues seguimos trabajando incansablemente, pero cuando empezamos hace 5 años, no se disponía en Europa de una base de datos de Derecho Animal, que incluyera los datos mencionados desde una perspectiva internacional, de la UE, estatal, autonómica y local como la que entonces creamos. Ahora la web derechoanimal.info, ofrece en abierto una base de datos única, que pone a disposición del usuario toda la normativa actualizada y, lo que aún es más original, toda la jurisprudencia completamente al día.

En el 2010 los tribunales de justicia españoles eran más bien parcos en dictar sentencias relativas a los animales, pues había menos denuncias y muchas de ellas se archivaban. En este breve lapso de tiempo, podemos decir que se ha producido un aumento exponencial muy notable de sentencias en Derecho Animal, fruto de un cambio social visible en una mayor sensibilización hacia los animales, que se advierte en haberse extendido lo que yo denomino "la cultura de la denuncia", o "el no a volver la cara hacia otro lado" cuando se maltrata a un animal. Este cambio tan positivo se ha producido de una manera silenciosa, pero desde este observatorio que constituye la web derechoanimal.info, podemos hacer esta afirmación de forma solvente. El seguimiento de la actividad jurisprudencial, la hacemos a través de una nueva sección de la web, "Noticias de los Tribunales", que nació de la necesidad que acabo de exponer y que se publica mensualmente, como el resto de contenidos de la web. En dicha sección se recogen todas las sentencias, de todas las instancias, de forma ordenada y accesible a los lectores. Del mismo modo, creamos desde el principio, con la sección "Novedades legislativas", un Boletín de noticias de leyes, tanto de proyectos, reformas, promulgaciones como de actualizaciones y derogaciones. El material que hemos reunido, es un instrumento indispensable para todo operador jurídico, pero tenemos lectores muy agradecidos a este esfuerzo entre los veterinarios, los servicios de la Administración, las Fuerzas de Seguridad, los gestores de Refugios de Animales y Asociaciones de protección Animal y, por supuesto, entre los estudiantes del Grado de Derecho, que cursan la materia de "Derecho y Bienestar Animal", en la Facultad de Derecho de la UAB, como entre los alumnos del Máster en Derecho Animal y Sociedad.

Por cierto, la expresión Derecho Animal, hoy completamente aceptada, parecía extraña hace 5 años a los profesionales del Derecho. Me alegro de que hoy ya no sea así!. Con toda naturalidad, se habla y se escribe hoy en castellano de Derecho Animal; en esa parcela del saber creo que, honestamente, estamos contribuyendo a crear una rama emergente del Derecho, por sí misma transversal e internacional. Desde el Grupo de Investigación SGR, ADS-UAB (Animales-Derecho-Sociedad), que da soporte a todas estas actividades en torno al Derecho Animal, procuramos incentivar publicaciones[1] , proyectos[2] , organización de Congresos[3] y reuniones científicas[4] , tesis doctorales[5] , trabajos de fín de Máster, trabajos de fín de Grado en Derecho, buscando siempre una estrecha colaboración con la ciencia Veterinaria[6] , gracias a la que el Derecho está cubriendo etapas de forma cada vez más consciente y firme, en defensa de los Animales y en la búsqueda de una salud integral para todos ("One Health")[7] 
Nacimos con el propósito de servir a la sociedad desde el Derecho, en favor de uno de sus componentes más olvidados, los Animales. Pensamos que todo lo que mejora nuestra relación con los Animales, compañeros de vida, ciudadanos de la misma patria común (patria communis), nos mejora como personas y mejora a la sociedad. Este es uno de los grandes retos jurídicos del S.XXI, hacer factible que el Derecho reconozca a los animales como lo que son y se sostiene ya, desde hace décadas, en el ámbito de la legislación de la UE: seres sintientes ("sentient beings")[8] En este sentido, nos alegra hacernos eco de la decisión de Francia de cambiar en breve el Code civil, para reconocer a los animales como "êtres vivants et sensibles", en cuyo proceso tomamos parte muy activa desde sus inicios y hemos venido informando puntualmente de ello[9].

Otro logro de estos años, ha sido consolidar las secciones con las que nació la web y crear otras nuevas. Somos un vector de los cambios jurídicos y sociales que se producen en torno a los animales y, para ello, como nos propusimos, cubrimos tanto una vertiente científica como formativa. Por nuestras páginas han desfilado, en estos años, las mejores firmas de los especialistas reconocidos mundialmente en Derecho Animal, como David Favre, de quien la web registra en este momento nada menos que 32 entradas, con artículos[10] , videos de sus clases en el Master en Derecho Animal y Sociedad, entrevistas y colaboración en la dirección de Trabajos de Final de Máster, Codirección de Tesis doctorales. El Prof. Favre, junto con El Dr. Enrique Alonso, y los Prof. Lluis Ferrer (Tufts University), Peter Singer (Princeton University), David Wolfson (NYU) y Steven Wise (President of Non-Human Rights Project), forman parte del Consejo Asesor de la web y ayudan, con su contrastada experiencia, a mantener nuestra misión de trabajo duradero en favor de los Animales. Nuestro agradecimiento es inmenso.

Publicamos mensualmente artículos científicos y de información general, documentos de estudio, comentarios de sentencias, análisis de libros, crónicas de Congresos y noticias actualizadas en la prensa de todo lo que conforma el universo animal, desde una perspectiva global. Nuestro mensaje tiene siempre una forma positiva, sin eludir los aspectos que, en relación con los animales, pueden y deben mejorarse y creemos que estamos contribuyendo, y mucho!, a dicha mejora. La web tiene muchos seguidores, a los que agradecemos su apoyo y estímulo constante, pero deseamos llegar a más y trabajamos en ello. Somos un equipo joven y experimentado, entusiasta y sereno, trabajadores voluntarios en un proyecto que cada día crece y muestra su influencia por el cambio en favor de los animales.

Una ojeada al Consejo editorial, permite apreciar la diversidad de procedencias y de formación de los miembros del mismo. Mencionarlos uno por uno, es un deber de agradecimiento y de reconocimiento por una labor en la que todos hemos ido creciendo. Gracias a Anna Mulà, desde el principio; al Dr. Carlos Contreras, que gestiona nuestros proyectos y va a comenzar a colaborar como editor adjunto; a María González Lacabex, Cristina Bécares, Irene Jiménez López e Irene García Colell, que son el gran equipo responsable de la actualización legislativa y jurisprudencial de la web, junto con el Dr. José Manuel Ríos Corbacho; a Martina Pluda, nuestra responsable de Comunicación, junto con Loïs Lelanchon, Nuria Murlà y Elisabet Miras que con sus conocimientos y dinamicidad, nos hacen presentes en las redes sociales y nos mantienen al día, exigentes, para que nos renovemos en la búsqueda de nuevos temas de interés y en la forma de presentarlos a nuestros lectores; los correctores de textos, Jessica Steffen, Carly Souther y $\mathrm{M}^{\mathrm{a}}$ Isabel Aristizábal son grandes talentos que nos permiten un diálogo crítico y fructífero con todos los colaboradores, que envían sus trabajos para publicar en la web; los corresponsales de la web, que nos mantienen al día de las noticias y actividades dedicadas a los animales, son un grupo que le da dimensión global a nuestra voz por los Animales: Elizabeth Romero y Samuel León (México), Julia Havenstein (Alemania), Moe Honjo (Japón y Asia), Carly Souther (USA), Dr. Tagore Trajano y Jéssica Steffen (Brasil), Juan Ignacio Sierra (Argentina), Sabine Brels (Francia) y Carla Campanaro (Italia). Por último, dos colaboradores sin los que la web no hubiera tenido el impulso para crecer y renovarse, me refiero a Oriol Caudevilla y a Daniel Parsons, ambos han sido, en diferentes momentos, un punto de referencia en la labor editorial y siempre cuento con ellos con profundo agradecimiento. Y, cómo no!, a Fernanda Rebagliati, a cuyo conocimiento de la fotografía, debemos las imágenes que ilustran y dan personalidad a la web

Como Fundadora y Editora de la web, sólo tengo palabras de gratitud para la Fundación Affinity, que nos brinda el soporte necesario para seguir adelante y que desde el principio nos ha mostrado su confianza y aliento apostando por nosotros. Igualmente, la Universitat Autònoma de Barcelona y especialmente la 
Facultat de Dret, nos animan, constantemente, a seguir siendo pioneros en Derecho Animal con un respaldo institucional a un proyecto al que nos mantenemos fieles: entonces y ahora nos proponíamos ser "la web de los Animales con Derecho" y después del tiempo transcurrido, podemos decir que somos "la web de los Animales de pleno Derecho".

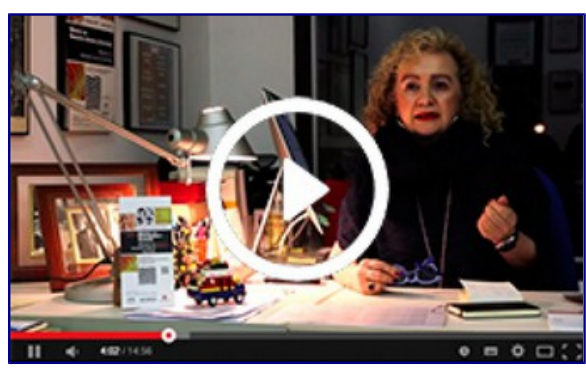

LA EDITORA

Teresa Giménez-Candela

Catedrática de Derecho Romano

Directora del Master en Derecho Animal y Sociedad

Directora del SGR Grupo de Investigación ADS

Universitat Autònoma de Barcelona

Sígueme en Facebook: https://www.facebook.com/editora.da

[1] La editorial jurídica "Tirant lo Blanch", pionera en España en publicaciones sobre la incidencia del Derecho en los Animales, ha creado la colección "Animales y Derecho", bajo mi dirección, de la que se esperan dos volúmenes en breve. Más información, en la entrevista: " Una nueva colección de 'Tirant lo Blanch' con proyección internacional.

[2] Entre otros, destacamos aquí la admisión de los animales de compañía en el Metro de Barcelona, que fue, en su origen, un Proyecto de investigación subvencionado por el Ajuntament de Barcelona. Vid. GIMÉNEZ-CANDELA, M., "Investigación jurídica aplicada: perros en el Metro de Barcelona"

[3] En Octubre de 2011, organizamos el Minding Animlas Pre-Conference, "Animals and the Law",. En Julio de 2014, en colaboración con la State University of Michigan y la Lewis \& Clark University, organizamos la II Global Animal Law Conference.

[4] En el apartado Actividades/Eventos de la web, puede apreciarse la intensa actividad desarrollada por los miembros del Grupo de Investigación, que ha figurado como coorganizador de eventos tanto en España como en el extranjero, señalamos, entre otros, "Enforcement of European Animal Welfare related Legislation, celebrada en Bruselas en Junio de 2012.

[5] En junio de 2014, se leyó en la Facultat de Dret de la Universitat Autònoma de Barcelona, la primera tesis doctoral en Derecho Animal en España, "Carlos Contreras, primer Doctor de España en Derecho Animal.

[6] Vid. en el apartado Actividades/Eventos de la web, algunos de los Seminarios y Workshops organizados en colaboración con la DG SANCO de la CE y la Facultat de Veterinaria de la UAB. Destacamos, entre otros: "First Workshop for Veterinary Practitioners. Improving Animal Welfare: a practical Approach".

[7] Vid. ampliamente, One Health Initiative, de la que es miembro la Federation of Veterinarians of Europe.

[8] GIMÉNEZ-CANDELA,M.,Introducción:

"Sólo tres textos constitucionales europeos (Suiza, Alemania y Austria) incluyen el bienestar animal -la consideración del animal como una parte del patrimonio común que el Estado debe proteger y conservar-, en la norma regente del ordenamiento jurídico, la que refleja los valores de una sociedad. Otros países europeos, desde hace años, han promulgado normas de relevancia en el tema que es objeto de nuestra atención. A través de esta web, pretendemos hacer llegar una información lo más exhaustiva posible del estado de la legislación sobre animales en nuestro entorno. Hoy en día, nuestros conocimientos ya no pueden quedar reducidos a un entorno próximo, porque las dimensiones del tema que nos preocupa, la mejora de la vida de los animales, es global".

[9] Desde el principio tomamos parte activa en el proceso, que ha culminado ahora con esta importante declaración, como puede verse en, GIMÉNEZ-CANDELA,M., A cara descubierta en favor de los animales: Francia, el Code civil y la Constitución.

[10] FAVRE, D., Judicial Recognition of the interests od Animals: a New Tort; Equitable Self-Ownership for Animals. 